Identity Formation among Novice Academic Teachers - a Longitudinal Study

Neil McLean \& Linda Price

Dr Neil McLean, Academic \& Professional Development Division, The London School of Economics and Political Science, Houghton Street, London, WC2A 2AE. n.d.mclean@1se.ac.uk

Professor Linda Price, Director of Academic and Organisational Development, University of Bedfordshire, Park Square, Luton, LU1 3JU

Neil McLean, ORCHID ID: 0000-0002-8718-0870

Linda Price, ORCHID ID: 0000-0001-5291-0469 


\section{Identity Formation among Novice Academic Teachers - a Longitudinal Study}

This study reports findings from an in-depth, longitudinal investigation of the formation of 13 novice tutors' professional identities as academic teachers. The study spanned tutors' first two years in-service, while they were also participating in a teacher development course.

Discourse was analysed across 65 time-series coursework texts, completed as part of the tutors' reflection on their teaching practice. The analysis captured the use of explicit identity positioning cues by tutors across the texts. Four discreet identity positions were catalogued: academic insider, class teacher, teaching course participant and young academic. The study illustrates how these tutors developed more complex identity narratives with enriched coherence over time as they reported negotiating challenges and dissonance between initial expectations and actual teaching experiences. This finding offers explanatory support for previous research regarding the value of longer-term teacher development programmes and illuminates existing theoretical models with practitioner perspectives.

Keywords: academic identity; identity formation; identity positioning; academic development; discourse analysis

\section{Introduction}

Educational research into academic identity formation has investigated the multifaceted nature of professional development (Clegg, 2005). Typically, academic identity studies are underpinned by sociological theory (McLean, 2012), where identity formation is examined through interactions between individual agency and social structures. It has included research into the individual agency in terms of selfefficacy, expectations and ambitions, personal meaning making and life stories (Deem \& Lucas, 2007; McAlpine \& Lucas, 2011; Remmik, Karm, Haamer, \& Lepp, 2011; Robertson \& Bond, 2005) as well as structures, such as discipline, department, institutional policies, and teaching cultures (Archer, 2008; Kahn, 2009; Knight \& Trowler, 2000; Neumann \& Becher, 2002; Smith, 2010). Of particular interest is how teacher development courses influence identity formation (Gibbs \& Coffey, 2004; Hanbury, Prosser, \& Rickinson, 2008; Postareff, Lindblom-Ylänne, \& Nevgi, 2007).

Research into academic identity has rarely investigated academics' own discourse in terms of how this achieves identity positioning. Previous research principally uses self-reporting to investigate research participants' experiences of entering and developing within the academy. In contrast, methods in psychological theory and research on identity and discourse explore 'what we do' to enact identity positions in different contexts and company (Jørgensen \& Phillips, 2002). This approach comprehends identity as flexible, performed and negotiated in interactions with others (Davies \& Harre, 1990). Discursive psychological analysis focuses on actual interactions as participants enter social situations and perform roles with new people.

Remmik et al. (2011) liken the negotiation of professional identity to an 'argument', where identity positioning involves making claims about holders of given social roles. These are often presented as 
narratives of self and entail a coherent biographical element (Acker \& Armenti, 2004; Gergen, 1994). MacAlpine \& Amundsen (2011) coined this 'identity trajectory', to highlight how individuals link pastpresent-future experiences in articulating their developmental journey and in justifying their current beliefs and practices. This study adds to this research through the use of discursive psychological methods, which identify and catalogue the discursive practices that achieve identity positioning (Benwell \& Stokoe, 2006; McLean, 2012). This enables a longitudinal approach to examining the emergent and complex nature of identity formation by studying the use of identity positioning cues over time.

\section{Method}

This study analysed the discursive practices of 13 novice social science seminar tutors as they claimed and negotiated identity positions during their first two years as teachers, while also on a teacher-training course. The time series spanned pre-service writing to texts written at the end of each of their first four teaching terms (two in each academic year). Participants were chosen on the basis of having no previous teaching experience. The five assignments tutors wrote in the time series had a word guide of 2000 words. The analysis for this study encompasses 65 time-series transcripts (approximately 120,000 words). The analysis was of naturally occurring texts that were written as part of these tutors' career development. The analytical focus was on how tutors explicitly identified themselves in their writing. The data analysis process combined discursive psychological discourse analysis and thematic analysis (Braun \& Clarke, 2006; Edley, 2001). Data analysis was conducted on paper copies of the texts, with one researcher initially cataloguing all explicit identity positioning cues present in each text. This researcher then inferred organising themes from these catalogues of cues, initially for each participant in each assignment. Then global themes were inferred from the organising themes captured across participants and assignments. The second researcher independently verified this initial coding and subsequent thematic analysis. This is illustrated in Table 1.

\section{[Table 1 goes here]}

Table 1: Overview of the stages of discourse and thematic analysis

Explicit identity positioning was investigated by identifying three discursive practices: 'direct labelling of self', 'othering', and 'direct address'. These cues were chosen for two reasons. First, they are 'explicit' and therefore unambiguously identifiable in participants' writing. Second, these cues are prevalent in reflective writing in a developmental context. This is because participants on such courses are asked to reflect on their own experiences, which leads to narratives of self that are delivered through self-referential cues and relational cues referring to others. Further, the course and assignment writing context also invited 'direct address' through the conventional academic writing behaviour of 'signposting' the overall structure of the assignment and key points that participants were going to address. Table 2 demonstrates how participants positioned themselves using these cues. 


\section{[Table 2 goes here]}

Table 2: Discursive practices analysed in the study

\subsection{Considerations regarding the use of 'naturally-occurring data'}

The texts that the 13 social science tutors wrote were originally a course requirement. After course completion, participants were asked for permission to allow their work to be analysed. The use of such data raises questions about the impact of the context on the communication in the texts. Contextual influence is inescapable: it always influences communication choices and performance (Yates, Taylor, \& Wetherell, 2001). This is also true in the unusual context of research interviews (Clegg \& Stevenson, 2013) and a starting assumption of this study is that there are no 'neutral' situations or examples of 'pure' data (Clegg, 2005).

The reason for choosing assignment texts as a data source is that these documents provide examples of authentic language use that includes identity positioning cues. The texts are the actual context in which the study participants presented themselves as academic teachers to an institutional audience. Rather than using reflection or self-reporting from the secondary data of interview transcripts, this naturally occurring data is a primary data source from a set of interactions in which these aspiring academics formed professional identities as part of their training as academic teachers. This enabled us to study their actual interactions as academic teachers. It is the case that in other interactions as academic teachers (with students or supervisors), these tutors may have positioned themselves somewhat differently. However, these texts provide time-series interactions in a professional context in which these tutors positioned themselves as particular kinds of academic teachers across their first two years in-service.

It is of course the case that tutors' writing was influenced by the assignment guidelines. These guidelines framed the topics they wrote about and the order in which they did so. The guidelines also required certain actions, such as reading and referencing educational literature. Data analysis considered this, and we catalogued cues and inferred organising themes within the context of each assignment first, with awareness of how the guidelines framed the interactive context. Two points are worth making however. The first is that the analysis was of identity positioning cues, rather than the 'substantive content' of the assignments. We were asking 'how did they present themselves?' rather than asking 'what did they choose to write about?' These positioning cues occurred across the texts and were neither directly requested in the guidelines, nor dependent on the content that the different assignments addressed. Secondly, the guidelines themselves were open prompts, rather than closed or guiding questions. In this regard, they were similar to the question frames used in interviews. As an example, for the second assignment, participants were asked 'What issues have your students faced this year?' / 'How might learning theory help to explain these issues? / How can students be supported in addressing these issues?' The guidelines therefore influenced 
participants in that they were required to discuss 'issues'. However, which issues they chose to raise was for them to decide. See table 3 for a description of the assignments and the guidelines. 


\section{[Table 3 goes here]}

Table 3 The assignment guidelines for the teacher development course texts

\section{Findings}

\subsection{Four Identity Positions}

The use of discourse analysis across the texts allowed the cataloguing of four identity positions that tutors explicitly adopted in their writing.

\section{[Table 4 goes here]}

Table 4: The four identity positions tutors claimed in their writing

\subsection{Shifting identity positioning - overcoming dissonant teaching experiences}

The key finding of this study is that across the participants, a common shift was identifiable in how they presented themselves as academic teachers over time. For clarity, this shift is presented in three distinct 'stages' in Figure 1. All tutors' identity positioning followed this trajectory, but there was diversity between participants in terms of rate and extent of change and in their disciplinary and teaching settings.

\section{[figure 1 goes here]}

Figure 1: Overview of the shifting identity positioning among tutors

The line in Figure 1 represents a trajectory of high initial expectations and early successes, through a stage of difficulty and dissonance and on to a stage of greater competence and self-confidence. For tutors, 'idealistic' pre-service expectations and positive early experiences were based on tutors' own preparation and positivity. However, this was both hard work for tutors and relatively short-lived. The dip in the line represents dissonance between pre-service expectations and the lived reality of teaching (leading to a more 'realist' presentation of self). This time was difficult for all tutors, though in different ways and to different degrees depending on personal strengths, circumstances and focus. The rising line on the right represents how tutors learned to cope and their competence and self-efficacy increase as they learned to succeed on their own terms ('independent' presentation of self).

\section{3 'Idealism'}

In the first stage, tutors' writing reflected an 'idealistic' perspective on teaching and learning. Pre-service, tutors wrote about themselves as 'academic insiders'. They felt that their successful student careers meant that they could act as 'guides' on the basis of their own success as students. Tutors discussed teaching in uncomplicated terms. They expected their students to learn as they had. They felt their courses were well designed and that full-time faculty were benign. Idealism was also present in their presentation of themselves 
as participants on the teacher development programme. They presented educational research uncritically and projected rather absolute proposals for how to teach students, characterised by homogeneity. The rising line in Figure 1 reflects their enthusiasm and the early successes they experienced on the basis of their preparation and good will.

\subsubsection{The 'academic insider' identity position}

This identity position was explicitly claimed in pre-service writing and in some texts after tutors' first term of teaching. It served to offer legitimacy as they began their careers. Legitimacy has been found to be an important aspect of academic development (Remmik et al., 2011; Ylijoki, 2000), as well as a comforting claim to be able to make. Figure 2 provides an overview of the thematic analysis of the frames of reference used with this identity position.

\section{[Figure 2 goes here]}

Figure 2: Organising themes for the 'academic insider' identity position

Values and role models: Tutors justified their values about education on the basis of their own study experiences, and through examples of good teachers (role models).

\footnotetext{
'When I think about examples of teaching I have been exposed to, there are several good and bad experiences that come to mind. I found myself appreciating those who seemed to put a fair amount of effort into preparation of their classes, who didn't think that frantic note taking was a sign of learning but rather gave you a copy of their notes.' (Participant 5)

'In developing my own teaching practice, I draw upon my own experiences as a learner, during which I have encountered various types of teaching styles.' (Participant 11)
}

Tutors also based their teaching expectations and planning on their own study experiences. In particular, tutors applied their own study preferences to how they expected their students to learn.

'I am also a very visual learner. Maps, graphs, even related comic strips that can spur discussion have a great effect in helping me to explore different avenues of thought as well as retain knowledge.'

These tutors' pre-service expectations reflected their own values based on who they had appreciated as teachers, and how they themselves had succeeded as students. There is almost no intimation that students will differ in what they appreciate and prefer. A key self-definition of the 'insider' role is as a 'guide' for students on the basis of their own successful study. Tutors who positioned themselves as 'insiders', tended to 
conceptualise students homogenously as mini-academics, who should behave as they themselves behaved as PhD students.

Disciplinary knowledge: When tutors identified themselves as 'insiders' in the study of their discipline, they made reference to their own content knowledge. Two more mature tutors also referred to their practitioner knowledge and careers.

'I think the course ... is quite well set up .... There are manifold entrance points to the literature. The readings are presented extremely helpfully with bibliographic notes about each topic that present and situate the literature and a suggested overall question for discussion.' (Participant 1)

However, there is very limited discussion of how students might struggle to learn this content. It is uncritically assumed that they will follow the pathways tutors themselves took.

An interesting temporal development was that the 'academic insider' position disappeared from how tutors positioned themselves. By the end of their first teaching term, tutors almost completely stopped referring to themselves as successful teachers on the basis of previous student successes or requisite content knowledge. Instead they transitioned to justifying their values and teaching approaches on the basis of acting in the role of 'class teacher'.

\subsubsection{The 'class teacher' identity position}

Adopting the identity position of a 'class teacher' differed from the 'academic insider' in terms of replacing focus on relevant personal history with reference to the inherited or ascribed social role. However, each tutor enacted this role differently. Thematic analysis of the explicit positioning cues distinguished the following organising themes for the 'class teacher', and related 'teaching course participant' identity positions.

\section{[Figure 3 goes here]}

Figure 3: Organising themes of the 'class teacher' identity position

The relationship between the 'class teacher' and 'course participant' identity positions is hierarchical. Tutors were only on the teaching course because they were class teachers with plans for careers in academia. The two positions share organising themes of reference to tutors' own teaching, students and courses, with the 'course participant' also entailing organising themes of educational research and explicit reflection on teaching. The two positions were claimed in all texts and explicit identity positioning in both identity positions follows the 'idealist'/'realist'/'independent' trajectory of stages. 
3.3.2.1 'Class teacher' as 'Idealist': Identity positioning in this stage is characterised by a general optimism and lack of criticality. For example, this is present in the organising theme of the 'course tutors were teaching on'.

'I think that the course structure is appropriate. It equips the students with some basic theoretical tools in the light of which they can then consider the questions raised in the second part of the course.' (Participant 4)

'The advantages of the current assessment process are that it allows work to be marked fairly and reduces the possibility of cheating, favouritism and plagiarism...' (Participant 3)

Teaching plans and experiences: In addition to this general lack of criticality, the 'idealist' stage also relates to tutors initially identifying teaching as a guidance activity. Tutors expected to exert 'direction' and thus 'ensure', student learning.

'The idea is to guide them not towards right or wrong answers but rather towards how to make a strong argument for a position, to feel comfortable defending that position, or adapting it as the case may be, when challenged.' (Participant 1)

'I have also tried to place the topic for the week in an historical context, and also related it to prior and future topics, as well as to the relevant positions in the literature. As the readings do not by their nature perform this task, I have taken it upon myself to provide a road map for the class each week.' (Participant 9)

Students: Another feature in this writing is how students tend to be treated as a relatively homogenous group. Appreciation of diversity among their students came later and was linked to the lived experience of how this diversity challenged tutors' intention to 'direct' and 'ensure' student learning. In earlier writing students were grouped uniformly.

'I want my students to be able to email me with their problems about the course materials ... I see this as fundamental to my role of ensuring that the students understand the course materials being covered on the course.' (Participant 6)

\subsection{3 'Teaching Course Participant' as 'Idealist'}

Tutors' initial presentation of themselves as course participants tended to focus on completing the assignments. Their discussion of their teaching environment tended to be descriptive, and accepting of 'how things are'. Participants enacted the 'course participant' role by citing educational literature, as with the earlier 'class teacher' position, a general lack of criticality is present. Use of literature involved quoting or paraphrasing, followed by statements of how this agrees with their own teaching experiences. 
'A leading current theorist, Stefano Guzzini, provides us with a tremendously useful categorisation of actually existing models of teaching IR ... My view of this excellent classification is that in an ideal world, a good exemplar of each of the four approaches would be present in an IR student's course selection.' (Participant 1)

Similar to the 'class teacher' 'idealist' stage, early reflections from the 'teaching course participant' position also presents rather absolute solutions to teaching based on readings.

'.. as Carlile and Jordan (2005) note, it encourages teachers to be role models, and to actively show students models of good practice. I have tried to do this in my class in numerous ways, including giving the first presentation in class in the Michaelmas term.' (Participant 9)

This quote demonstrates the 'idealist' stage of both the 'class teacher' and 'teaching course participant' identity positions. In both, tutors tended to describe their students as an undifferentiated and homogenous group, and presented teaching as a relatively simple endeavour.

\section{4 'Realism'}

The optimistic 'ideal' stage was followed by more criticality and emotional writing by the end of the first and second terms. The dip in Figure 1 reflects the dissonance experienced by their enthusiasm and effort not being met with equal effort from students. It also stemmed from being more aware of the course weaknesses and the assessment systems, and not being able to change them. Tutors also became aware of the limitations of full-time faculty, and of students. As teaching course participants, they were more critical of the literature, contrasting educational arguments with their own teaching experiences. As their expectations about 'guiding' willing students were not met, they used their course readings as a vocabulary to critique their educational contexts, highlight student diversity and the dissonance between their and others' expectations and their teaching realities.

\subsection{1 'Class teacher' as 'Realist'}

Over time, the lack of criticality of the 'idealist' stage passed, and focus shifted to challenges. Tutors wrote about a lack of alignment between student actions and their 'idealist' expectations; discussions around failure and complexity emerge. This complexity relates to students' diversity and their differing motivations and world perspectives. It also relates to the impacts of differing educational practices and structures.

Presentation of self as 'class teachers' becomes critical and emotional, with course convenors also 'othered' for their lack of communication, care and knowledge. Earlier emphasis on 'ensuring learning' is replaced by statements about the limits of what can be expected of tutors. 
How tutors came to describe the courses they were teaching on: This greater criticality is evident toward the end of second term writing, where tutors linked course structures and practices with student, and tutor, difficulties.

'One reason why the students in my class may not automatically be linking theory and practice is the structure of the course that makes them seem mutually exclusive.' (Participant 2)

'Formative marking is carried out entirely by the class teachers, with negligible guidance.' (Participant 7)

Teaching plans and experiences: In addition to criticality of course structures, increasing reference is made to the challenges of teaching and learning and the limits of a teacher's control:

'One disappointing result for me this year was that a few students who could have benefitted from more attention did not choose to come to see me after class or in my office hours. is one such student. Although I gave him very detailed feedback on his essays, and encouraged him to come and see me, he never came to my office hours.' (Participant 9) 'Regarding the students themselves, it seemed that they felt less confident speaking in front of the entire class ... This forced me to reconsider my approach to class teaching, and to adopt the method of group work.' (Participant 8)

Students: As awareness of the limits of directing students grew, tutors started to focus more on contributing to learning. For example, Participant 6 moved away from the early expectation to 'ensure' learning:

'Recognising that I cannot be in charge of students' learning, given the diversity of experiences, constructs and capabilities, I view my role fundamentally as a facilitator of class discussions.'

These quotes show how tutors were relating themselves to their teaching situations in very different ways to the 'idealist' stage.

\subsection{2 'Teaching course participant' as 'Realist'}

Positioning as 'teaching course participant' also changed with time. This coincided with the increased criticality of the 'class teacher' identity position and shared the 'class teacher' themes of student diversity and problems with course structures and 'unintended' learning outcomes for their course:

'... the course content is strongly cognitivist in that it is almost exclusively made up of works which address the higher levels in Bloom's taxonomy ... It emphasises analysis, evaluation and synthesis, whereas knowledge (i.e. empirical data on Western politics) is presented only insofar as it is required for these primary purposes...' (Participant 3 ) 
Educational research: Presentation of self as a course participant in texts written following tutors' second and third terms of teaching share this criticality. Tutors questioned teaching course material and arguments.

'I am sceptical of the relevance of Kolb \& Kolb's 'experiential learning theory' to my own approach to teaching ... their learning theory is mostly social constructivist in orientation, with some repetition in the emphasis in 're-learning"' (Participant 10)

'It seems that the 'objectivist' school of teaching - whereby knowledge is understood to be imparted, then tested - is not necessarily a model to be thrown out wholesale even in the context of new ideas about the superiority of a non-dualistic model that breaks down the strict notion that a teacher teaches and a student learns (Biggs, 2004).' (Participant 13)

This criticality was absent in the 'idealist' stage writing.

\section{5 'Independence'}

A third 'independent' stage is evident in all tutors' writing completed during year two. Tutors explained the terms on which they chose to teach, given the complexities of their teaching situation and their educational goals. As 'class teachers', tutors reflected on why and how they were implementing principled teaching. As 'teaching course participants', tutors combined educational and disciplinary research perspectives, and underpinned practice with theory. And, as 'young academics' some tutors presented themselves as having gone beyond the role of 'class teacher' to become members of their disciplinary tribe. The rising line in Figure 1 represents this increasing competence and sense of self-efficacy.

\subsection{1 'Class teacher' as 'Independent'}

This shift was evident in the thematic analysis of tutors' positioning as 'class teachers'. This moved beyond the reaction, and rejection, of the 'realist' stage, to more pro-active and self-confident 'independent' positioning.

Combining themes - teaching plans and experiences/students/discipline/course structures: In texts written at the end of term four, tutors' 'independence' from others, such as course convenors and students, is a marked feature of positioning cues. In their second year, tutors' discussion of teaching and learning also becomes increasingly complex. This stems from two sources. Firstly, tutors tended to combine reference to the different organising themes listed above. Secondly, positioning in this writing combines tutors' initial values and plans as 'class teachers' with greater understanding of teaching and learning as a result of actual experience. As a result, approaches to teaching are presented as effective and sensible compromises, not as absolute solutions.

The following short self-narrative shows how 'complexity' is present in discussions of student diversity and the impact of contextual factors. Participant 4's espoused response claims experience over 
time, knowledge of a range of teaching techniques, judgement on curricular coverage and the confidence to make her own decisions. This judgement and these decisions were apparently made independently from the course convenor:

'As with last year, it was challenging to keep the diverse range of students interested, making questions challenging enough to interest the more able students, yet not making them so challenging that the less able were alienated - especially at $4 \& 5$ on a Friday! The main changes that I made during this course, based on the previous year, were changing the scope of some of the tasks where the ground to be covered in the seminar had proved too wide to fit into the time available and I added some different tasks, such as discussion of case studies and quizzes, to add more variety.'

This progression from 'idealist' to 'realist' and to a confident 'independent' positioning reflects other research into the impacts of longer term pedagogical training (Postareff et al., 2007). Further, the integration of the different organising themes for the 'class teacher' position, outlined in Figure 3, exemplifies an 'expanding awareness', identified in the Conceptions of Teaching (CoT) literature (Åkerlind, 2003).

\subsection{2 'Teaching course participant' as 'Independent'}

As 'course participants', tutors' later positioning was also more confident. There is also a degree of reversal from the 'idealist' positioning. In early writing, tutors tended to refer first to their reading and then to their experiences. Later, tutors increasingly reflected on their own teaching experiences, supported with literature underpinning their experiential reasoning. This led to presentations of self as 'course participants' combining their lived experiences, contexts and aims with input from the course, rather than following the ideas of others. Participant 12 illustrates this shift:

'...my approach to teaching, and in providing feedback, ... has been oriented by constructivist approaches to learning that include: an emphasis on critical rather than passive thinking (Duron 2006); building criticality on individual knowledge and experience (Carlile \& Jordan 2005, p.19; Kolb \& Kolb 2005, p.19); and addressing the individual learning needs of students (Carlile $\&$ Jordan 2005, p.19). Such student-centred approaches to learning are now widely accepted. However, this is not the case with feedback and assessment, which is still "generally conceptualised as a transmission process” (Nicol \& MacFarlane-Dick 2006, p.200).'

This 'independent' stage appears in tutors' later writing alongside enactment of the 'class teacher' position. However, it is also contemporary to a new identity position, termed 'young academic'. 


\subsubsection{The 'young academic' Identity Position}

A fourth identity position identified in the analysis was explicitly claimed in 11 of the 13 participants' writing towards the end of their second year (see figure 4). This positioning was done through reference to self as a disciplinary academic, either explicitly in the first person ('I'), or by association with a disciplinary community in the fourth person ('we'). What is new about the 'young academic' position is that tutors claimed to belong to academia as academics, rather than as the successful students of the 'academic insider' positioning.

\section{[Figure 4 goes here]}

Figure 4: Organising themes for the 'young academic' identity position

Disciplinary community: Tutors' explicit claims to belong to academia were made in different ways. For example, through positioning themselves as experts in teaching the discipline:

'.. to match the delivery of education to our aspirations, we need to consider above all, if we are really interested in quality, how we design the fabric of the educational experience students receive. That is, we need to revisit the design of degree courses and programmes on the basis of Nygaard et al.'s pointers as to what an academic education is actually supposed to be providing in a discipline, rather than what we as specialist academics, are interested in.' (Participant 1)

Another approach was to discuss academic life from the position of an insider.

'As teachers, we must acknowledge our role in generating knowledge and fostering skills.

Finding the time to reflect on our days, the interactions we may have had in the classroom and the opportunities we may have taken or missed to advance learning is increasingly difficult in an academic organisational culture that values measurable output over all other types of outcomes.' (Participant 2)

This new position was also claimed through 'othering' identity positions previously held such as class teacher:

'It would also be worth considering a non-compulsory short essay ... However, this is not the norm at the University of , so may meet with resistance from both students and class teachers.' (Participant 4)

'The aim of this type of assessment is to give students more flexibility in their learning ... For a class teacher, "letting go" in this way may produce some anxiety about the direction of the essays...' (Participant 13) 
Pedagogical content knowledge: Despite the claim to belong to disciplinary communities, tutors' positioning as 'young academics' is particularly about belonging as a 'good' academic. This encompasses rejection of traditional or departmental approaches to teaching their disciplines in favour of pedagogically aware disciplinary academics.

'These outcomes serve as good examples for my area of International Relations. They are specific and measurable and correspond with Mager's understanding of what makes a good learning outcome ... In contrast, the 'aims and objectives' of (course code), cited below, are less well defined, prioritising aims over outcomes:' (Participant 1)

'(course code) is still constructed in the traditional manner, focussing on the knowledge which the course intends to impart and implicitly adopting the perspective of the academic whose task it is to do the imparting.' (Participant 3)

Another key theme is that pedagogic content knowledge (Shulman, 1987) is applied beyond class teaching. This was possible in all the assignments, but is only a feature of the final assignments on course design. Earlier assignments saw fairly pragmatic discussions of teaching course content. In contrast, the 'young academic' identity position asserts tutors' competence over choices about teaching relevant research areas and literature as disciplinary scholars.

'I think that although the current ordering of the topics is appropriate, the weighting of time attributed to each topic should be rebalanced. I suggest 3 weeks on consequentialism, 4 weeks on deontology and 3 weeks on virtue ethics. This would allow the students to study virtue ethics in more detail than the current structure allows.' (Participant 4)

'Similarly, we can observe trends amongst students who study political philosophy at university level ... students will generally have a genuine interest in philosophy (there is little money in the field to act as an incentive!) and will have read some of the canonical literature before coming to university; they will prefer abstract reasoning to quantitative work; they also generally have an interest in public affairs and often wish to pursue a career in academia, politics, NGOs, or think tank research.' (Participant 6)

\section{Summary of the Analysis of Explicit Positioning Cues}

Two kinds of professional identity position emerged in this study. One grounded in competently fulfilling ascribed roles (class teacher/teaching course participant). The other relates to community and belonging ('academic insider'/'young academic'). The 'academic insider' position, and associations with personal biographies as a successful student, was replaced as teaching experience grew. The two role-specific identity positions shifted from initial 'idealism' to a 'realism' borne of dissonance between expectations and lived 
reality. As this dissonance normalised, tutors increasingly presented themselves as 'independent' and competent on their own terms. The emergence of 'independent' positioning informed and coincided with new claims to belonging to disciplinary communities as 'young academics'.

These findings resonate with existing research into academic identity formation where self-narratives pass through earlier life stages or roles (Acker \& Armenti, 2004). These narratives develop through overcoming challenges and dissonance within particular contexts (McAlpine \& Lucas, 2011). This study also offers insight into the 'expanding awareness' (Åkerlind, 2003) aspect of the CoTs literature. In particular, the longitudinal profiles in this study provide cases of tutors moving from focus on themselves (ITTF) to an understanding of complexity and focus on learning (CCSF) (González, 2011). This change is associated with initial expectations of simply 'guiding' students failing because of the complexity of real-world learning and teaching. The dissonance also echoes Clegg's (2008) findings of the importance of changing identity positions and the rejection of expectations, whether one's own or those of colleagues or departments'. It also reflects developmental stage models (Kugel, 1993; Sprague \& Nyquist, 1989; Staton \& Darling, 1989), where teaching assistants were found to move from less sophisticated to more complex stages as a response to challenges in their teaching and research.

\section{Conclusion}

This study provides insight into how novice social science tutors formed identities as academic teachers over their first two years in-service. The longitudinal methodology facilitates an in-depth study of how identity is co-constructed over time through an examination of explicit identity positioning cues. Movement between positioning stages reflects a developing biography as an academic teacher, which reflects the lived experience of teaching (McAlpine \& Lucas, 2011). Of particular interest is how tutors replaced reference to their student pasts with reference to their teaching experiences as they claimed legitimacy as academic teachers. Then further, how they claimed legitimacy as class and later as disciplinary teachers and as members of an academic community on the basis of their competence and knowledge. However, this study raises questions as to whether certain aspects of academic teaching identity are hierarchical, as presented in the CoTs literature. For example, in this study the 'class teacher' and the 'teaching course participant' positions developed in parallel, although not necessarily at the same rate. Hence certain aspects of development may be co-constructed and co-developed.

This study also contributes to the mounting evidence of the benefits of longer-term teacher development programmes. It provides an account of how such programmes lead to greater self-efficacy (Postareff et al., 2007; Remmik \& Karm, 2009) and to the development of teaching repertoires (Coffey \& Gibbs, 2002). Writing iteratively about different aspects of teaching, where practice and research are integrated in reflection, is a forum for identity formation through presentation of self. In this context, this is presentation of self by aspiring academics to members of a teacher development course team. This presentation of self was as an informed and reflective academic teacher and as Davies and Harre point out: 
'Among the products of discursive practices are the very persons who engage in them' (1990, p. 283).

Teacher development programmes provide participants with a new vocabulary to represent their teaching actions and values, in particular as they experience challenge as new academic teachers. Such courses also offer a space to reflect on the complexity encompassed in teaching and learning in higher education. This study demonstrates the value of this process of iterative critical reflection, conducted over an extended time period, and this study's findings reinforce the notion that longer-term teacher development programmes are valuable for the development of aspiring and early career academics.

(Word count -6773 - including 813 of references) 


\section{References}

Acker, S., \& Armenti, C. (2004). Sleepless in Academia. Gender and Education, 16(1), 3-24.

Åkerlind, G. S. (2003). Growing and developing as a university teacher: Variation in meaning. Studies in Higher Education, 28(4), 375-390.

Archer, L. (2008). The new neoliberal subjects? Young/er academics' constructions of professional identity. Journal of Education Policy, 23(3), 265-285.

Benwell, B., \& Stokoe, E. (2006). Discourse and Identity. Edinburgh: Edinburgh University Press.

Braun, V., \& Clarke, V. (2006). Using thematic analysis in psychology. Qualitative Research in Psychology, 3, 77-101.

Clegg, S. (2005). Theorising the mundane: The significance of agency. International Studies in the Sociology of Education, 15(2), 149-164.

Clegg, S. (2008). Academic identities under threat? British Educational Research Journal, 34(3), 329-345.

Clegg, S., \& Stevenson, J. (2013). The interview reconsidered: Context, genre, reflexivity and interpretation in sociological approaches to interviews in higher education research. Higher Education Research \& Development, 32(1), 5-16.

Coffey, M., \& Gibbs, G. (2002). Measuring teachers' repertoire of teaching methods. Assessment \& Evaluation in Higher Education, 27(4), 383-390.

Davies, B., \& Harre, R. (1990). Positioning: The discursive production of selves. Journal for the Theory of Social Behaviour, 20(1), 43-63.

Deem, R., \& Lucas, L. (2007). Research and teaching cultures in two contrasting UK policy contexts: Academic life in education departments in five English and Scottish universities. Higher Education, 54(1), 115-133.

Edley, N. (2001). Analysing masculinity: Interpretative repertoires, ideological dilemmas and subject positions. In M. Wetherell, S. Taylor \& S. J. Yates (Eds.), Discourse as data: A guide for analysis (pp. 189-228). Milton Keynes: The Open University.

Gergen, K. J. (1994). Exploring the postmodern: Perils or potentials? American Psychologist, 49(5), 412.

Gibbs, G., \& Coffey, M. (2004). The impact of training of university teachers on their teaching skills, their approach to teaching and the approach to learning of their students. Active Learning in Higher Education, 5(1), 87-100.

González, C. (2011). Extending research on 'conceptions of teaching': Commonalities and differences in recent investigations. Teaching in Higher Education, 16(1), 65-80.

Hanbury, A., Prosser, M., \& Rickinson, M. (2008). The differential impact of UK accredited teaching development programmes on academics' approaches to teaching. Studies in Higher Education, 33(4), 469-483.

Jørgensen, M. W., \& Phillips, L. J. (2002). Discourse Analysis as Theory and Method. London: Sage.

Kahn, P. (2009). Contexts for teaching and the exercise of agency in early career academics: Perspectives from realist social theory. International Journal for Academic Development, 14(3), 197-207. 
Knight, P. T., \& Trowler, P. R. (2000). Department-level cultures and the improvement of learning and teaching. Studies in Higher Education, 25(1), 69-83.

Kugel, P. (1993). How professors develop as teachers. Studies in Higher Education, 18(3), 315-328.

Lave, J., \& Wenger, E. (1998). Communities of Practice: Learning, Meaning, and Identity. Cambridge: Cambridge University Press.

McAlpine, L., \& Amundsen, C. (Eds.). (2011). Doctoral Education: Research-Based Strategies for Doctoral Students, Supervisors and Administrators. New York: Springer.

McAlpine, L., \& Lucas, L. (2011). Different places, different specialisms: Similar questions of doctoral identities under construction. Teaching in Higher Education, 16(6), 695-706.

McLean, N. (2012). Researching academic identity: using discursive psychology as an approach. International Journal for Academic Development, 17(2), 97-108.

Neumann, R., \& Becher, T. (2002). Teaching and learning in their disciplinary contexts: A conceptual analysis. Studies in Higher Education, 27(4), 405-417.

Postareff, L., Lindblom-Ylänne, S., \& Nevgi, A. (2007). The effect of pedagogical training on teaching in higher education. Teaching and Teacher Education, 23(5), 557-571.

Remmik, M., \& Karm, M. (2009). Impact of training on the teaching skills of university lecturers: Challenges and opportunities. Haridus, 11(12), 20-26.

Remmik, M., Karm, M., Haamer, A., \& Lepp, L. (2011). Early-career academics' learning in academic communities. International Journal for Academic Development, 16(3), 187-199.

Robertson, J., \& Bond, C. (2005). Being in the university. In R. Barnett (Ed.), Reshaping the University: New Relationships between Research, Scholarship and Teaching. (pp. 79-91). Maidenhead: Open University Press.

Shulman, L. S. (1987). Knowledge and teaching: Foundations of the new reform. Harvard Educational Review, 57(1), 1-23.

Smith, J. (2010). Forging identities: The experiences of probationary lecturers in the UK. Studies in Higher Education, 35(5), 577-591.

Sprague, J., \& Nyquist, J. D. (1989). TA supervision. New Directions for Teaching and Learning, 39, 37-53.

Staton, A. Q., \& Darling, A. L. (1989). Socialization of teaching assistants. New Directions for Teaching and Learning, 1989(39), 15-22.

Yates, S. J., Taylor, S., \& Wetherell, M. (2001). Discourse Theory and Practice: A Reader. London: Sage.

Ylijoki, O.-H. (2000). Disciplinary cultures and the moral order of studying: A case-study of four Finnish university departments. Higher Education, 39(3), 339-362. 